nitrogen by the action of I part of the chlorine were independent of the formation of nitrogen trichloride by another part, the constant relation of I volume of nitrogen to 6 volumes of chlorine would be improbable. The following hypothesis as to the cause of this relationship is given with some hesitation and in the hope that it may lead to discussion and to a further consideration of similar cases. If we suppose, what seems not inherently improbable, that all reactions involving the decomposition of molecules are preceded by an ionization of the parts of those molecules, it would follow that elementary molecules, as well, may ionize into positive and negative parts. This explanation of the reaction may be represented graphically thus :

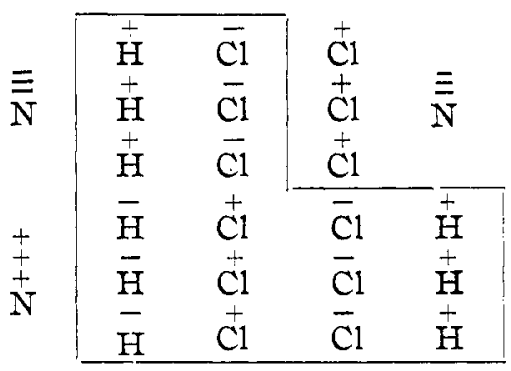

The explanation given involves the further idea that in the ionization of ammonia the hydrogen may become either positive or negative. When we remember the neutral character of ammonia and the fact that its hydrogen may be replaced by either chlorine or sodium, such a thought is not so improbable as it seems when first presented.

That the hypothesis here suggested is capable of a wide application need hardly be said.

TERre HaUte, IND., May I5, 190 I.

\title{
THE BOILING-POINT CURVE FOR MIXTURES OF ETHYL ALCOHOL AND WATER.
}

By WrLIIAM A, NOYES AND R, R. WARFEL. 1

Received June 5, 1901.

T has long been known that it is impossible to obtain absolute alcohol from dilute alcohol by distillation. Some years ago Le $\mathrm{Bel}^{2}$ showed, also, that a 98 per cent. alcohol could be separated

1 An account of the work here described was presented to the Faculty of the Rose Polytechnic Institute as a thesis for the Degree of Bachelor of Science.

2 Compt, rend., 88, 912. 
by fractional distillation into an alcohol of 97.4 per cent. (by volume), and a residue containing 99.5 per cent. While these facts demonstrate that the boiling-point of absolute alcohol must be higher than that of alcohol slightly diluted, no one, so far as we can learn, has proved this by means of a direct determination.

The determination of the boiling-point curve for alcohol-water by J. K. Haywood, ${ }^{1}$ has come to our notice since reading the proof of this article. Haywood entirely overlooked the minimum point. His curve, from alcohol of 85 per cent. down, agrees satisfactorily with ours.

The boiling-point apparatus of $\mathrm{H}$. C. Jones ${ }^{2}$ was used for the determinations. The tube of the condenser was sealed to the side tube of the apparatus, and was protected from the entrance of moisture at the top by means of a tutbe filled with calcium chloride. A small glass tube was inserted through the cork beside the thermometer, for the introduction of water or alcohol.

The alcohol used was rendered absolute by boiling twice with quickline, the second time with the addition of a small amount of barium oxide. In distilling it, the first and last portions were rejected. The specific gravity of the alcohol indicated a strength of 99.98 per cent.

The boiling-points for alcohol from Ioo per cent. to 64 per cent. were determined with a Beckmann thermometer graduated to $1 / 100^{\circ}$. Those from 64 per cent. to o per cent. were determined with a normal Green thermometer graduated in $0.1^{\circ}$. To determine the value of the degrees of the Beckmann thermometer the apparatus was connected with a large llask and a manometer, and the alcohol was boiled under diminished and also under increased pressure. In this way it was found that a difference of $\mathrm{r} \mathrm{mm}$. in pressure caused, at atmospheric pressure, a change of $0.0333^{\circ}$ in the boiling-point. Ramsay and Young's tables give $0.0339^{\circ}$ for I $\mathrm{mm}$. The value of the degrees was, accordingly, taken as being sufficiently accurate for the present purpose.

To find the value of the Beckmann readings in terms of the true thermometer scale, pure water was placed in the apparatus, and it was connected with a large bottle and a marometer. The pressure was then reduced till the water boiled at about $80^{\circ}$ of the true scale and a series of readings of thermometer, barometer,

1 J. Phys. Chem., 3, 318.

2 Am. Chem. J., 19, 581 .

if. Chem. Soc. (London), 47, 640 . 
and manometer were taken. The barometer and manometer readings were corrected to $0^{\circ}$ and by comparison with Regnault's tables for the vapor-pressure of water, the point on the true thermometer corresponding to the readings of the Beckmann thermometer was determined. From this value the boiling-point of absolute alcohol under a pressure of $760 \mathrm{~mm}$. is, as determined by us, $78.33^{\circ}$. The boiling-point calculated from the tables of Ramsay and Young is $78.30^{\circ}$. As Ramsay and Young doubt. less had much more accurate means than we could command for measuring heights of manometer and barometer, we have based our tables on their value for the boiling-point, instead of our own.

The barometer used was of the siphon form. The scale was compared with a standard scale by means of a dividing engine before it was filled; and the necessary correction applied. . It was filled by ourselves, the mercury being boiled under diminished pressure during the filling.

In carrying out a series of determinations a weighed amount of alcohol or of water, or, in some cases of dilute alcohol, was put into the apparatus and the boiling-point determined. A weighed amount of water or alcohol was then added and the determination repeated. Each time, the barometer and its temperature were also read. The results were then corrected to a basis of $760 \mathrm{~mm}$. by adding or subtracting $1_{30}^{\circ}$ for each $\mathrm{I} \mathrm{mm}$. difference in pressure. The nature of the readings will be apparent from the following illustration. In correcting the barometer readings a plus correction of $\mathrm{I} \mathrm{mm}$. for error of scale is included.

\begin{tabular}{|c|c|c|c|c|c|c|}
\hline $\begin{array}{l}\text { Grams of } \\
\text { water } \\
\text { added. }\end{array}$ & Barometer. & Temperature. & $\begin{array}{l}\text { ERIES } 7 . \\
\text { Barometer } \\
\text { corrected } \\
\text { to zero. }\end{array}$ & $\begin{array}{l}\text { Beckman } \\
\text { readings. }\end{array}$ & $\begin{array}{l}\text { Beckmann } \\
\text { readings cor- } \\
\text { rected to } \\
760 \mathrm{~mm} \text {. }\end{array}$ & $\begin{array}{l}\text { Per cent. } \\
\text { of alcohol. }\end{array}$ \\
\hline 0,0000 & 737.6 & I9.5 & 736.13 & $2.94^{8}$ & 3.744 & $99.9^{8}$ \\
\hline 0.2128 & 737.9 & 20.0 & $73^{6.37}$ & 2.925 & 3.713 & $99.5^{I}$ \\
\hline 0.2440 & 737.95 & 20.0 & 736.42 & 2.907 & 3.693 & 98.97 \\
\hline 0.1790 & 738.0 & 18.0 & 736.72 & 2.895 & $3.67 \mathrm{I}$ & $98.5^{8}$ \\
\hline$\ldots$. & $\ldots$ & $\cdots$ & $\ldots \ldots$ & $\ldots$ & $\ldots$ & $\ldots$ \\
\hline$\ldots$. & $\ldots \ldots$ & $\ldots$ & $\ldots$. & $\ldots$ & $\ldots$ & $\ldots$ \\
\hline 0.2900 & 743.5 & 17.5 & 742.28 & 3.089 & 3.680 & 92.42 \\
\hline 0.2860 & 743.7 & 17.5 & 742.48 & 3.115 & 3.699 & 92.10 \\
\hline
\end{tabular}

Started with 44.478 grams of alcohol of 99.98 per cent.

Six series of experiments, made before the use of the apparatus had been sufficiently mastered, were rejected. Four series

${ }^{1}$ Loc, cit. 
which gave fairly concordant results were used to obtain mean values for the range from alcohol of 100 per cent. to 92 per cent. From these series the following values for each change of onehalf per cent. in the amount of water were calculated by interpolation.

$\begin{array}{ccccccc}\begin{array}{c}\text { Per cent. } \\ \text { of alcohol. }\end{array} & 7 . & 8 . & \text { Io. } & \text { Ir. } & \text { Mean. } & \\ \text { Io0.0 } & 3.745 & 3.738 & 3.756 & 3.759 & 3.750 & 0.030 \\ 99.5 & 3.714 & 3.708 & 3.727 & 3.730 & 3.720 & 0.027 \\ 99.0 & 3.695 & 3.680 & 3.700 & 3.698 & 3.693 & 0.021 \\ 98.5 & 3.669 & 3.655 & 3.687 & 3.678 & 3.672 & 0.017 \\ 98.0 & 3.653 & 3.639 & 3.674 & 3.654 & 3.655 & 0.016 \\ 97.5 & 3.638 & 3.625 & 3.658 & 3.634 & 3.639 & 0.008 \\ 97.0 & 3.620 & 3.619 & 3.651 & 3.632 & 3.63 \mathrm{I} & 0.004 \\ 96.5 & 3.624 & 3.612 & 3.643 & 3.629 & 3.627 & 0.003 \\ 96.0 & 3.626 & 3.613 & 3.633 & 3.625 & 3.624 & 0.002 \\ 95.5 & 3.627 & 3.613 & 3.634 & 3.632 & 3.626 & 0.001 \\ 95.0 & 3.625 & 3.611 & 3.638 & 3.633 & 3.627 & 0.009 \\ 94.5 & 3.636 & 3.623 & 3.647 & 3.639 & 3.636 & 0.009 \\ 94.0 & 3.635 & 3.630 & 3.660 & 3.655 & 3.645 & 0.016 \\ 93.5 & 3.653 & 3.644 & 3.678 & 3.668 & 3.661 & 0.016 \\ 93.0 & 3.672 & 3.656 & 3.698 & 3.682 & 3.677 & 0.014 \\ 92.5 & 3.679 & 3.667 & 3.713 & 3.705 & 3.691 & 0.018 \\ 92.0 & 3.694 & 3.685 & 3.728 & 3.728 & 3.709 & \end{array}$

The remainder of the boiling-point curve possesses less interest and it was not attempted to secure the same degree of accuracy. From alcohol of 92 per cent. to 65 per cent. two series of determinations were made and the Beckmann thermometer was used.

For alcohol from 65 per cent. to o per cent., two series were made and the normal Green thermometer was used. As a part of the stem of the thermometer was outside of the apparatus a stem correction from the tables of Rimbach ${ }^{1}$ was used. The correction for the thermometer at $100^{\circ}$ was determined in the apparatus with pure water and the correction at $80^{\circ}$ was determined by comparison with the Beckmann thermometer, whose value had been determined as described above. As the two corrections were different a table of corrections for intervening degrees was calculated on the supposition that the scale of the thermometer was uniform.

The final results of all the series are as follows:

i Ber, d. chem. Ges., 22, 3075. 


$\begin{array}{cccccc}\begin{array}{c}\text { Per cent. } \\ \text { of alcohol. }\end{array} & \begin{array}{c}\text { Boiling. } \\ \text { point. }\end{array} & \begin{array}{c}\text { Per cent. } \\ \text { of alcohol. }\end{array} & \begin{array}{c}\text { Boiling- } \\ \text { point. }\end{array} & \begin{array}{c}\text { Per cent. } \\ \text { of alcohol. }\end{array} & \begin{array}{c}\text { Boiling- } \\ \text { point. }\end{array} \\ \text { I00.0 } & 78.300 & 88.0 & 78.445 & 55.0 & 81.77 \\ 99.5 & 78.270 & 87.0 & 78.530 & 48.0 & 82.43 \\ 99.0 & 78.243 & 86.0 & 78.575 & 37.0 & 83.76 \\ 98.5 & 78.222 & 85.0 & 78.645 & 35.0 & 83.87 \\ 98.0 & 78.205 & 84.0 & 78.723 & 29.0 & 84.86 \\ 97.5 & 78.19 \mathrm{I} & 83.0 & 78.806 & 26.0 & 85.4 \mathrm{I} \\ 97.0 & 78.18 \mathrm{r} & 82.0 & 78.879 & 22.0 & 86.1 \mathrm{I} \\ 96.5 & 78.179 & 81.0 & 78.968 & 20.0 & 87.32 \\ 96.0 & 78.174 & 80.0 & 79.050 & 18.0 & 87.92 \\ 95.5 & 78.176 & 79.0 & 79.133 & 13.0 & 90.02 \\ 95.0 & 78.177 & 78.0 & 79.214 & 10.0 & 91.80 \\ 94.5 & 78.186 & 77.0 & 79.354 & 8.0 & 93.10 \\ 94.0 & 78.195 & 76.0 & 79.404 & 7.0 & 93.73 \\ 93.5 & 78.21 \mathrm{I} & 75.0 & 79.505 & 5.50 & 94.84 \\ 93.0 & 78.227 & 73.0 & 79.683 & 4.50 & 95.63 \\ 92.5 & 78.24 \mathrm{I} & 71.0 & 78.862 & 3.0 & 97.1 \mathrm{I} \\ 92.0 & 78.259 & 69.0 & 80.042 & 2.0 & 98.05 \\ 91.0 & 78.270 & 67.0 & 80.237 & 1.50 & 98.55 \\ 90.0 & 78.323 & 65.0 & 80.438 & 1.00 & 98.95 \\ 89.0 & 78.385 & 63.0 & 80.642 & 0.50 & 99.65\end{array}$

In the determination with small amounts of alcohol the readings of the thermometer were taken when the vapors first entered the condenser, as after boiling for a few minutes a relatively large proportion of the alcohol present would be found in the upper layers and in the condenser, and the thermometer under those conditions registered about 0.3 higher. It was shown by slow heating that the difference was not due to the lag of the thermometer.

An examination of the table and curve shows that the minimum boiling-point is for alcohol of 96 per cent. by weight. This corresponds to 97.45 per cent. by volume. Le $\mathrm{Bel}^{1}$ gives the minimum as at 97 per cent. (presumably by volume, though he does not make this statement). His method would tend to place the minimum too low, unless moisture was very carefully excluded.

In the accompanying figure the upper part gives the boilingpoint curve for alcohol of 90 to Ioo per cent. on an enlarged scale. The lower portion of the figure gives the complete curve.

It will be seen that the curve is steeper on the side toward absolute alcohol than on the other side. Alcohol of 90.7 per cent. has the same boiling-point as absolute alcohol. An inspection of the curve also shows very clearly why it is easy to concentrate

1 Loc cit. 


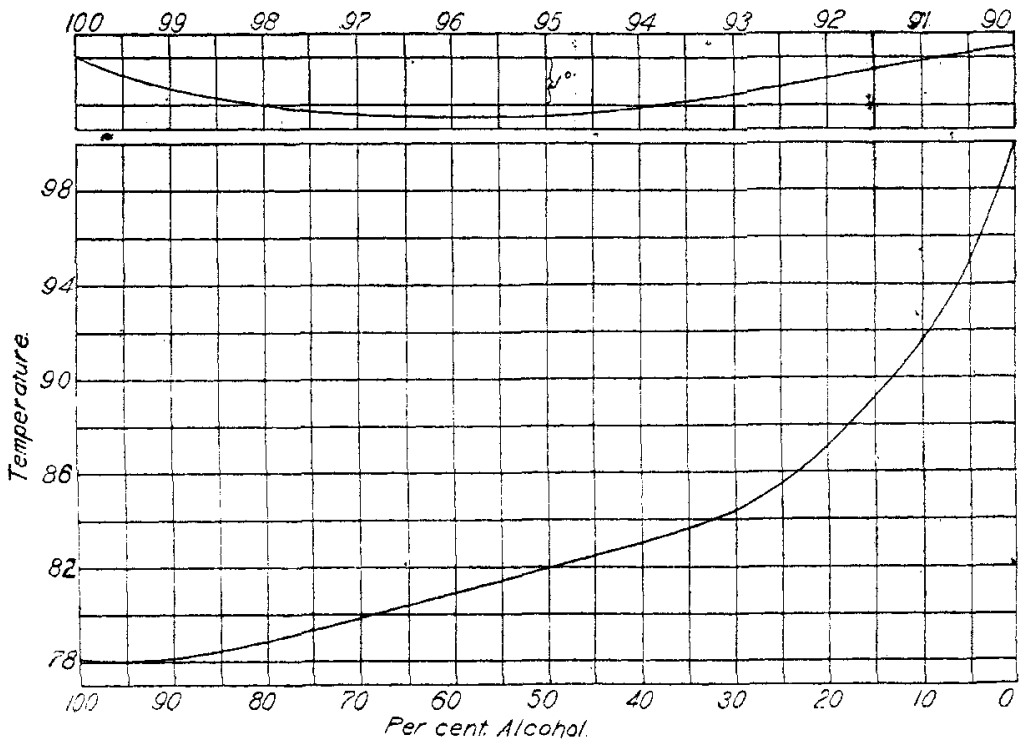

alcohol by distillation to a strength of 30 or 40 per cent. by weight, while the further concentration is relatively difficult.

ROSE POLYTEChNic INSTITUTE,

TERRE HACTE, June I, IgOI.

\section{THE VOLUMETRIC DETERIINATION OF ZINC.}

By Percy H. Walker.

Received May 15, Igot.

THE most commonly used method for the determination of zinc is the volumetric process of titrating with standard potassium ferrocyanide, using either a uranium solution or one of cobalt nitrate or platinum chloride as indicator. The ferrocyanide titration has several disadvantages. The standard solution does not keep well, and hence must be frequently standardized. If too much ferrocyanide is added in titrating, there is nothing to do but make another determination. The method of using an indicator, by taking out drops, invariably introduces an error.

R. K. Meade has given us a method based on an entirely different reaction. He precipitates the zinc as zinc ammonium arsenate, and uses this arsenate to liberate iodine, which is then titrated by thiosulphate.

The most satisfactory gravimetric process for determining zinc is the precipitation of zinc ammonium phosphate and weighing

1 This Journal, 22, 353 (1900), 